\title{
PEDAGOGÍA Y COMPROMISO
}

\author{
David Ravet*
}

RESUMEN: El autor, mediante ejemplos tomados de las obras de Albert Londres, Paul Nizan y Joseph Kessel, busca proponer una pedagogía del compromiso basada en tres ejes: el enfoque transcultural, la didáctica de la intertextualidad y la metodología de lo transartístico.

soes

ABSTRACT: The author, using examples taken from the works of Albert Londres, Paul Nizan, and Joseph Kessel, endeavors to propose a commitment pedagogy based on three central themes: the transcultural approach, the teaching of intertextuality, and the trans-artist methodology.

PALABRAS ClAVE: Pedagogía, compromiso, didáctica, enfoque transartístico, intertextualidad, relatos de viaje.

KEYWORDS: Pedagogy, commitment, teaching, trans-artist approach, Intertextuality, travel journals.

RECEPCIÓN: 19 de noviembre de 2009.

APROBACIÓN: 16 de diciembre de 2009.

*Université de la Sorbonne Nouvelle, Paris III. 
CITAM Derechos Reservados.

La reproducción total o parcial de este artículo se podrá hacer si el ITAM otorga la autorización previamente por escrito. 


\section{PEDAGOGÍA Y COMPROMISO*}

\section{Introducción}

$$
\text { ¿La pedagogía y el compromiso }
$$
son contradictorios o están ineludiblemente ligados en las clases de lengua? Nos inclinamos por la segunda respuesta. Una pedagogía del compromiso contrasta con una didáctica de lo lingüístico, es decir, una didáctica que se focaliza en los ejes pragmáticos de la lengua. Ciertamente, esta didáctica de lo lingüístico es necesaria, pero es imperfecta para hacer frente a los nuevos desafíos transculturales a los cuales se enfrentan los estudiantes de francés como lengua extranjera de nivel avanzado y superior. Por eso proponemos una pedagogía basada en problemáticas ideológicas, en temas políticos esenciales, debatidos sobre todo a lo largo del siglo XX por importantes escritores franceses $\mathrm{O}$ por grandes reporteros como André Gide, Paul Nizan, Céline, Joseph Kessel y Albert Londres.

Estos temas son: el colonialismo francés de los años 30 (Aden Arabia de Nizan y Viaje al Congo, Regreso de Chad de Gide); el capitalismo de los años 20 (Aden Arabia); el sistema penitenciario en la Guayana francesa (Au Bagne -En el presidio- de Albert Londres); el terrorismo en los Balcanes (Les Comitadjis -Los Comitadjis- de Albert Londres); la esclavitud en Abisinia o en Yemen (Marchés d'esclaves-Mercados de esclavos-de Kessel).

* Traducción de Maiala Meza, con la colaboración de Julián Meza. 
Para este artículo nos centraremos en nuestras investigaciones sobre literatura de viaje, didáctica de la literatura y pedagogía de lo transartístico, así como en los resultados de nuestra tesis defendida en noviembre de 2008 en la Universidad de París III: Didáctica de los textos de viaje del siglo XX para clases de francés como Lengua Extranjera de nivel superior, desde una perspectiva intercultural y transartística.

\section{Pedagogía del compromiso y enfoque transcultural}

Una pedagogía de la educación puede ser construida sobre tres ejes: el enfoque transcultural, la didáctica de la intertextualidad y la metodología de lo transartístico, que permiten la confrontación entre literatura, artes plásticas, música, fotografía, carteles, cine, etc. Estos tres ejes se combinan.

El enfoque transcultural a menudo es indisociable de la noción de transgresión y de subversión. Para nuestro corpus, existe una relación esencial entre la estética de la desmitificación, de la transgresión y las dimensiones transculturales de los textos de viajes.

Tomemos varios ejemplos de esta estética. En Aden Arabia Nizan utiliza la subversión para denunciar el viaje a las colonias y el sometimiento del hombre moderno por el capitalismo.

Esta estética es igualmente utilizada por Céline en el episodio africano de Viaje al fin de la noche, en el cual el escritor deconstruye fuertemente los estereotipos del colono racista y los mitos fundadores del colonialismo. Su forma de proceder es la sátira, "los retratos patológicos" de los colonos, el delirio verbal, la reescritura grotesca de los mitemas de la bajada a los Infiernos y la destrucción del lenguaje clásico. De esta manera, las relaciones transculturales entre Francia y África son representadas por Céline gracias a procesos literarios transgresivos. Esta transgresión debe ser analizada puesto que refuerza la condenación de la explotación del negro por el blanco.

Por otra parte, en Los Comitadjis de Albert Londres, de 1932, el reportero utiliza la desmitificación de los terroristas de la Organización 
Revolucionaria Interior Macedonia, así como la manera de denunciar, por medio de una serie de contrastes, la influencia y el control dictatorial de los terroristas en una región entera de Bulgaria. Escribe:

La sal de este viaje está en la inversión de las situaciones: en otros lugares los terroristas viven en bodegas, aquí la luz de Dios brilla para ellos. [...] El país de "La Libertad o la Muerte". Aquí viven los profesores del terrorismo: los viejos lentamente, los jóvenes vibrando de pasión. Alrededor de ellos, deferentes, atentos, estudiosos, se mueven los alumnos. Y el resto de la población trabaja para alimentarlos. [...] El asombro del primer día persiste al pasar de los días. Una Corte de los Milagros, un islote dudoso de gran ciudad, prohibiciones de entrada al país, eso se puede imaginar, ipero todo un país! ${ }^{1}$

La pedagogía de lo transcultural pasaría entonces por el estudio de los procesos literarios utilizados y consistiría en confrontarlos con la ideología de la opinión pública de la época. Se trataría de estudiar el carácter social, histórico y político de los viajes emprendidos, sus impactos o sus recepciones en Francia o en el extranjero. La pedagogía de lo transcultural presentará varios aspectos: estudio de la noción de extranjero, análisis de las formas y los papeles de las transgresiones literarias, confrontación de las ideologías del dominante y del dominado, estudio del contexto socio-histórico de las obras y del acogimiento de un texto en varios ambientes culturales.

Por ejemplo, en Viaje al fin de la noche, la mirada de Bardamu sobre los indígenas y sobre la colonización es original, oponiéndose al contexto histórico de los franceses. En efecto, en 1932, fecha de la publicación del Viaje y de Aden Arabia, los mitos coloniales se escenifican y transmiten a millones de europeos mediante la exposición colonial internacional de Vincennes, organizada por Lyautey. Para las autoridades coloniales se trata de convencer al público de que "el Imperio es un territorio necesario para que Francia siga siendo una gran potencia, de mostrarle la excelencia (y la existencia) de un 'método' colonial francés [...], de demostrar que Francia, patria de los derechos del Hombre,

${ }^{1}$ Albert Londres, Les Comitadjis, 2002, Serpent à Plumes, pp. 125, 129-30. 
lleva a los indígenas la Civilización y sus bienestares y que los educa para que se emancipen un día [...]; que a cambio el Imperio alimenta con sus frutos más bellos la economía francesa; finalmente, suscitar en los jóvenes una vocación de colono que el Imperio necesita". ${ }^{2}$

\section{Pedagogía del compromiso y didáctica de la intertextualidad}

Lo transcultural también integra la noción de intertextualidad. El profesor utilizará la intertextualidad como un estupendo motor de pedagogía. Esta didáctica de la intertextualidad permite al estudiante construir de manera muy coherente su capacidad cultural. Tomaremos como ejemplo el estudio de Aden Arabia de Nizan, donde esta didáctica resulta particularmente competitiva para delimitar mejor el texto de viaje, su carácter panfletario y su relación con los relatos de viaje tradicionales. Efectivamente, Nizan hace referencia o evoca numerosos textos de viaje, desde la Antigüedad hasta el siglo XVIII, como la Odisea de Homero, relatos utópicos, Diario de viaje de Montaigne, obras sobre viajes de Bougainville o de Voltaire. Exceptuando la Odisea, estas referencias son desviadas, reinterpretadas (a veces de manera falsa) y fuertemente criticadas por el autor, que de esta manera destruye los mitos del viaje exótico, del viaje a un paraíso perdido, y denuncia la experiencia viajera como una acción antirrevolucionaria. El viaje es percibido como una fuga, una escapatoria de los combates sociales esenciales en la lucha de clases. Así, Nizan escribe:

Poseemos una tradición raramente interrumpida del espacio geográfico [...]. Se remonta tan lejos como al principio del Renacimiento: es un tiempo donde las personas empezaban a estar hartas, en el cual tenían pasión por las historias de los paraísos terrestres perdidos y vueltos a encontrar, por las anécdotas morales sobre los buenos salvajes. [...]

Solamente la gente de Europa se aprovechó de la tierra conocida, medida, catastrada: en todos lados nos roban como en un bosque; los salva-

${ }^{2}$ Catherine Hodeir, Michel Pierre \& Sylviane Leprun, "Les expositions coloniales. Discours et images" en Nicolas Bancel, Pascal Blanchard \& Laurant Gervereau, (eds.) Images et colonies (1880-1962), 1993, Paris, BDIC/ACHAC, p. 129. 
jes virtuosos son clientes y esclavos. Los curas de todos los dioses blancos se han puesto a convertir a esos idólatras, a esos fetichistas, a hablarles de Lucero y de la Virgen de Lourdes [...]. Con la Eucaristía llega el trabajo forzado de Brazzaville-Océan. ${ }^{3}$

La didáctica de la intertextualidad se realiza en un primer momento por medio de la búsqueda de referencias textuales explícitas e implícitas inscritas en una obra, y después por el estudio de las funciones de estas referencias, de las transgresiones hechas por los autores y de su uso ideológico o político. La intertextualidad se une, entonces, con lo transcultural, en sus dimensiones transgresiva y política al mismo tiempo.

\section{El enfoque transartístico: Compromiso y Artes en la clase de lengua}

Las obras de viajes de nuestro corpus también encubren numerosas referencias de orden artístico. La didáctica de lo transartístico permite primero un estudio de estas referencias; pero su establecimiento y sus formas son mucho más complejos. La comparación transartística supone para el profesor el problema de la educación de los análisis prestados de otras formas artísticas como la pintura, la fotografía, el cine, los carteles o la música.

Nuestro enfoque permite desarrollar la competencia de los estudiantes, especialmente insertando los textos literarios en la historia de las estéticas o de los movimientos artísticos del siglo XX. También intenta renovar la didáctica de la literatura que ya no sólo se reduce al análisis del objeto literario, sino que se abre a uniones pluridisciplinarias enriquecedoras y creativas. Este enfoque transartístico sirve también de base para una didáctica del compromiso, utilizando los soportes icónicos y fílmicos que transportan de manera impresionante ideologías y mitos contemporáneos.

De esta manera, la confrontación entre textos anticolonialistas y carteles colonialistas publicitarios o de reclutamiento militar de 1930

${ }^{3}$ Idem, p. $72-4$. 
nos permite mostrar y analizar las temáticas y los mitos coloniales (“contribución de la civilización", "impureza de la raza negra", "canibalismo indígena", "superioridad del Blanco"), la política de discriminación de los Negros por las imágenes oficiales de la Metrópoli y su denuncia por parte de Céline, Nizan y Gide. En este pasaje de Aden Arabia, Nizan muestra bien la importancia y las apuestas sociales, económicas y políticas de la propaganda iconográfica:

Los Poderes conocían bastante bien esos deseos [de huir de la alienación social] para utilizarlos con los fines más brutales de su actividad: el reclutamiento masivo de marinos y militares de carrera, la paz sangrienta de sus experiencias coloniales. Los carteles de captación en la puerta de las gendarmerías, de los cuarteles, de los ayuntamientos, los artículos del Temps (Tiempo) colonial, explotaban con una astucia grosera el deseo que campesinos, obreros, empleados podían tener de escapar a su vieja piel: prometían con certeza alimento y cobijo, los placeres del trópico, la facilidad de mujeres de color, seduciendo los corazones a través de artificios que inspiraban un conocimiento elemental pero eficaz de las tentaciones humanas. ${ }^{4}$

La didáctica de lo interartístico toma diferentes formas y envites pedagógicos: creatividad de los estudiantes, combinación de la didáctica de lo intertextual y de la memoria de imágenes, adquisición y utilización del léxico pictórico, musical, fílmico y fotográfico. Permite trabajar sobre las transposiciones estéticas, simbólicas y políticas de un arte a otro, y particularmente sobre las nociones de arte comprometido y de propaganda.

Tomemos dos ejemplos: el reportaje de 1923, Au Bagne, de Albert Londres, confrontado con caricaturas y fotografías sobre los presidiarios en la Guyana francesa, y la comparación entre Mercado de esclavos, de Kessel y la representación pictórica de la esclavitud en el siglo XX de Salvador Dalí.

\footnotetext{
${ }^{4}$ Paul Nizan, Aden Arabia, 2002, Paris, La Découverte poche, p. 74-5.
} 


\section{Albert Londres: la prisión en literatura y en las artes}

Las experiencias de los viajes de Albert Londres se mezclan con un trabajo objetivo de revelación de las condiciones de vida de los presidiarios que se convierten, por un efecto de inversión, en las víctimas de un sistema represivo inicuo, inadaptado y finalmente asesino. Au Bagne es un reportaje sobre el infierno de la prisión guyana, que permitió a la opinión pública francesa y a las autoridades parlamentarias, tomar conciencia de las consecuencias desastrosas del sistema penitenciario, tanto en el plano humano como en el judicial e incluso económico (con una crítica virulenta de la gestión absurda de la colonia). Compararemos el reportaje viático de Albert Londres con las fotografías de las celdas y calabozos de la prisión de Guyana para analizar la relación entre reportaje y fotoperiodismo. De esta manera, la escritura de Albert Londres será confrontada con los procedimientos fotográficos utilizados para presentar el tema del encarcelamiento.

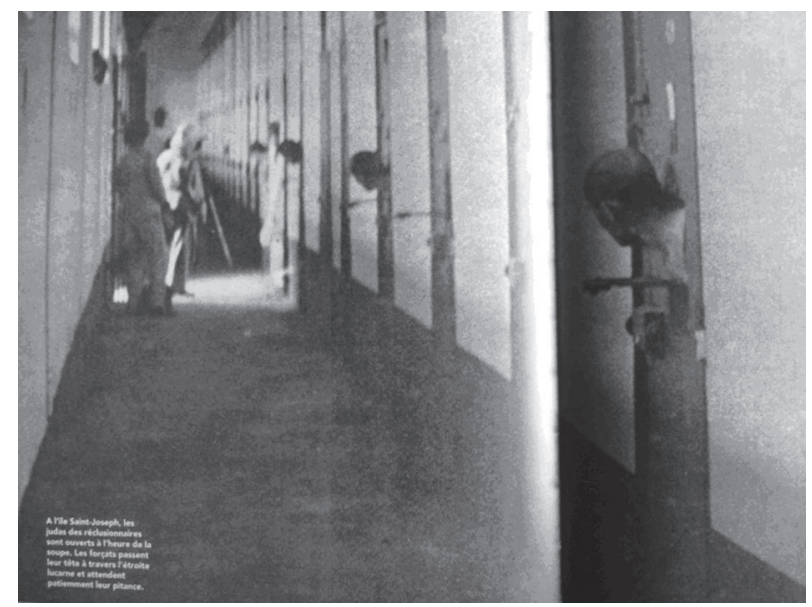

Fotografia del presidio aparecida en un artículo de periódico: "El presidio no es muerte", Paris Match, 11 de mayo de 1939. ${ }^{5}$ Leyenda: "En la isla Saint-Joseph, las mirillas de los reclusos se abren a la hora de la sopa. Los condenados pasan sus cabezas a través de la estrecha claraboya y esperan pacientemente su pitanza".

${ }^{5}$ Esta fotografía de los calabozos de la isla Saint-Joseph está reproducida en Jack Le Roux, La Guyane, le bagne: un siècle de presse illustrée de 1840 à 1940, 2006, Saint-Ouen l'Aumône, Les Éditions du Valhermeil, p. 140-1. 
Esta fotografía presenta una escena de la vida de los presidiarios en los calabozos de Saint-Joseph: la distribución de la ración de sopa. Esta imagen está construida con una perspectiva en diagonal muy grande, presentando al espectador las celdas de los presidiarios del más cercano al más lejano. Esta composición espacial en hilera subraya el aspecto bestial del encierro de los presidiarios. De esta manera, los calabozos aparecen como caballerizas. Este efecto se refuerza por el sujeto escogido por el fotógrafo: se trata de mostrar las cabezas de los presidiarios sobrepasando las mirillas de los calabozos a la hora de la comida. Las paredes, los pasillos, la altura de las celdas y del techo, los barrotes dominan casi todo el espacio de este lugar, en el cual la figura del hombre aparece muy reducida. Esta reducción de lo humano a una imagen de algunas cabezas rapadas y a dos cuerpos de guardianes pasa también por el procedimiento de desenfoque de la fotografía.

Esta fotografía puede ser comparada por los estudiantes de este pasaje de Au Bagne sobre los calabozos, poniendo en escena el primer encuentro entre el reportero y el presidiario Eugène Dieudonné:

No se abrió la puerta sino la mirilla. Apareció una cabeza como en una ventanilla de guillotina. [...] Él [Eugène Dieudonné] se veía forzado a encorvarse mucho. Su voz estaba cortada. Y es horrible hablar sólo a una cabeza. Rezaba por que abrieran. Abrieron. ${ }^{6}$

La reducción de lo humano a su cabeza pasando por la apertura de la mirilla se parece, según Albert Londres, al suplicio de la guillotina. El sistema de degradación de los condenados también es criticado por el fotógrafo a través de la leyenda de su imagen, especialmente por la utilización del término peyorativo "pitanza" en "Los condenados pasan sus cabezas a través de la estrecha claraboya y esperan pacientemente su pitanza." De esta manera, el texto permite reforzar el carácter denunciador de la fotografía.

\footnotetext{
${ }^{6}$ Albert Londres, Au Bagne, 1975, Paris, Union Générale d'Éditions, p. 86.
} 
Albert Londres no sólo denuncia las condiciones de detención de los presidiarios, sino que también condena la ausencia de una colonización justa y eficaz en la Guyana francesa.

En Au Bagne, el reportero se presenta como un ser compasivo y también como un vocero de los marginados y condenados. Entonces, adopta un punto de vista muy diferente al de sus contemporáneos, puesto que percibe y describe los acontecimientos en parte desde el prisma de los presidiarios y no por la mirada de los funcionarios del sistema penitenciario. Gracias a esta perspectiva, el viajero rehabilita la figura del presidiario minando los estereotipos negativos construidos por la sociedad, como, la imposibilidad de una enmienda real del condenado o de su relevo; su ausencia de moral o de dignidad; el mito de un condenado disfrutando del clima favorable o de la riqueza de la colonia francesa en la Guyana. Este último mito fue difundido en la metrópoli a principios del siglo XX, especialmente por caricaturistas como Jean Paul Plumet, en la revista l'Assiette au Beurre (El plato de mantequilla).

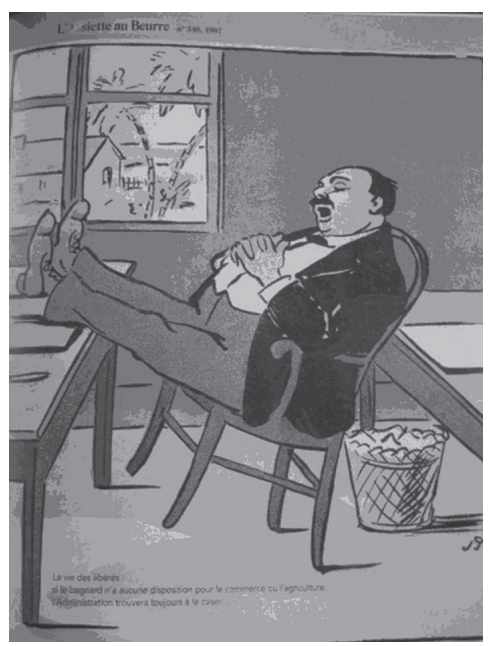

Jean Plumet, Caricatura del presidio en l'Assiette au Beurre, núm. 340 de 1907. Leyenda: "La vida de los liberados. Si el presidiario no tiene ninguna disposición para el comercio o la agricultura, la Administración siempre encontrará donde colocarlo"?

${ }^{7}$ Jean Plumet, ilustración de l'Assiette au Beurre, núm. 340 de 1907, reproducida en Le Roux, op. cit., p. 187. 
Jean Plumet presenta al presidiario liberado como un ser privilegiado. Transmite el mito de un liberado próspero mediante la caricatura de un presidiario obeso, vestido con un elegante traje de tres piezas, cómodamente instalado en un gran escritorio y descansando al fresco de la administración penitenciaria. La caricatura está reforzada por la disposición geométrica de la ilustración. La denuncia de la pereza del presidiario se enfatiza por la ausencia de papeles sobre los dos escritorios de la estancia y por la visión de un paisaje tropical encantador a través de la ventana. De esta manera, el presidiario liberado es percibido como una persona pudiente de la sociedad, que se aprovecha de los efectos benéficos de la colonización, así como de la generosidad y del laxismo de la administración carcelaria. Esta idea es subrayada por el texto de la leyenda: "La vida de los liberados. Si el presidiario no tiene ninguna disposición para el comercio o la agricultura, la $A d m i$ nistración siempre encontrará donde colocarlo." La administración penitenciaria es percibida por el caricaturista como un sistema filantrópico o caritativo al servicio de los condenados liberados. Ahora bien, Albert Londres demuestra absolutamente lo contrario gracias al relato de su experiencia viajera en la Guyana.

Como Albert Londres, Joseph Kessel se convierte en un escritorviajero comprometido desde 1920, y en 1930 condena con fuerza, en su reportaje Marchés d'esclaves, la supervivencia de la esclavitud en Abisinia, en Hedjaz y en Yemen.

\section{Joseph Kessel y Salvador Dalí: una condena de la esclavitud}

Kessel presenta a los esclavos en el primer capítulo de su reportaje, que hace eco con "la escena de la hoguera" del capítulo V. Ésta muestra la danza frenética y casi diabólica de los esclavos. Existen varios retratos que muestran el carácter primitivo y salvaje de los esclavos. Los estigmas físicos que la esclavitud produce sobre sus cuerpos son estudiados y relacionados por el reportero con los comportamiento psicológicos rudimentarios. El cliché del salvajismo de ese "pueblo 
de servidumbre" es atenuado por los relatos de la vida de los esclavos entrevistados por el viajero. De esta manera, pasamos del estereotipo a un nuevo posicionamiento humanista del reportero frente a los esclavos:

Se pusieron en cuclillas sobre sus talones, felices de saberse tratados humanamente. Les llevaron un té bien azucarado y el gran diablo dijo, mirando la brasa cubrirse de ceniza:

-Vengo de Tigré. Nací esclavo de un guerrero. No conocí ni a mi padre ni a mi madre. Seguí a mi amo por todos lados. Fue asesinado en un combate por un soldado de este país. Ahora lo sirvo a él". 9

Estos retratos se inscriben en una condena muy fuerte de la esclavitud que pasa por un viaje extraordinario sobre las huellas de los traficantes y de sus caravanas. Los retratos literarios de los esclavos hechos por Kessel pueden compararse con un lienzo de Dalí donde se inscribe una referencia literaria fuerte.

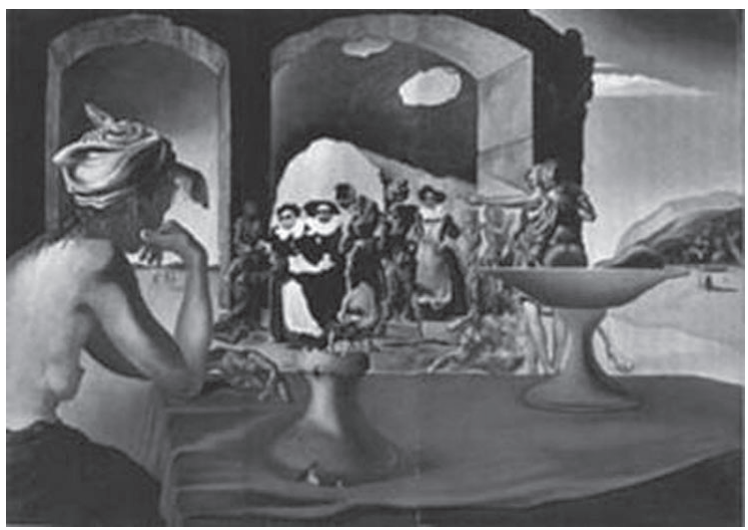

Salvador Dalí, Mercado de esclavos con la aparición del busto invisible de Voltaire, 1940.

Óleo sobre lienzo, 47 x 66 cm, Museo de San Petersburgo, Florida.

${ }^{8}$ Existe una animalización de los retratos de esclavos: "un rictus de fiera", "la hembra gorila", durante la escena sensacional de la laceración del buey; Joseph Kessel, Marchés d'esclaves, 1984, Paris, Union Générale d'Éditions, pp. 64-5.

${ }^{9}$ Idem., p. 69. 
Existen dos niveles de lectura del cuadro Mercado de esclavos con la aparición del busto invisible de Voltaire de 1940, de Salvador Dalí. En efecto, este cuadro presenta en primer plano a un esclavo viendo un mercado de esclavos situado en una caravana en medio de un paisaje desértico, y Dalí utiliza una figura ambigua representando el busto de Voltaire. De esta manera, el lienzo presenta una fuerte oposición entre las ideas tolerantes de la filosofía y de los escritos viáticos de Voltaire y la práctica inhumana de la esclavitud. A la figura ambigua utilizada por Dalí se sobrepone una referencia textual viajera más precisa. Otra originalidad del cuadro de Dalí reside en el punto de vista; efectivamente, el espectador del lienzo tiene el mismo punto de vista que el esclavo del primer plano, puesto que ambos miran hacia la escena del mercado de esclavos. Este proceso refuerza la condena de la esclavitud así como el efecto de la figura ambigua. Ciertamente, el busto de Voltaire se percibe o se yergue entre el esclavo y la escena del mercado. Este proceso de disposición espacial dramatiza la escena revelando a Voltaire como una figura concreta de la denuncia de la trata de seres humanos. El estudio de este cuadro por los estudiantes los inicia, no sólo en la interpretación pictórica de un tema central en el reportaje de Kessel, sino que también les permite estudiar la presencia de un símbolo fuerte de la literatura francesa de la Ilustración en un cuadro surrealista.

Las tomas de posición de Kessel y Londres son características de una nueva tendencia y concepción del gran reportaje de viaje con la idea de un papel activo del reportero. El reportero ya no sólo está presente en los países extranjeros para observar y describir situaciones o acontecimientos precisos, sino que también condena y desvela el sufrimiento de los hombres. Albert Londres y Joseph Kessel quieren mejorar las condiciones de vida de los más débiles y pesar en el combate político parlamentario. El enfoque transartístico Literatura-Artes plásticas es esencial para que los estudiantes entiendan y analicen las formas literarias de estos compromisos. 


\section{Los "recorridos culturales" de los estudiantes}

Las comparaciones interartísticas permiten crear verdaderos "recorridos culturales" para los estudiantes extranjeros. Estos "recorridos culturales" se pueden construir gracias al aprendizaje y al trabajo sobre las uniones de las referencias artísticas en el seno de una obra literaria o confrontadas con ellas. El "recorrido cultural" es una exploración casi infinita donde, detrás de cada referencia artística y cultural, se pueden esconder o despejar otras referencias de culturas o de épocas diferentes. De esta manera, cada estudiante podría construir su propio recorrido comparando y confrontando las obras del corpus del seminario con otras obras de su fondo cultural, de su país de origen o de su aire geográfico. Si el estudiante evoluciona en el seno de una clase multicultural y multilingüe podrá exponer y explicar a los otros estudiantes la construcción de su "recorrido cultural". Esto permitirá intercambios transculturales fructíferos. En cuanto al profesor, este podrá comparar los diferentes recorridos de los estudiantes y crear un espacio de interacción y de negociación en el seno de la clase. En efecto, la noción de "recorrido cultural interartístico" no se restringe a los problemas de influencia o de afinidad entre las obras; concierne también al viaje del estudiante extranjero a Francia o a los países francófonos y a sus descubrimientos artísticos.

\section{Conclusiones}

Este artículo intentó definir y presentar las formas de una pedagogía del compromiso literario. De esta manera, el profesor combinará el enfoque transcultural, el estudio intertextual y la metodología transartística para llegar a enseñar literatura y artes comprometidas sobre los sujetos políticos más o menos sensibles según los aires culturales. Estos tres ejes parecen competitivos para estudiar textos de viajes comprometidos del siglo XX, de Gide, Nizan, Céline, Albert Londres y Kessel. Nuestra concepción de una pedagogía de compromiso permite ya no restringir la didáctica del francés lengua extranjera a aspectos pura- 
mente gramaticales, lingüísticos e incluso informáticos, sino también replantearse una didáctica de las lenguas y de las culturas, de ahora en adelante orientada hacia las competencias culturales, argumentativas, críticas, transartísticas y creativas de los estudiantes. La pedagogía del compromiso literario y artístico también permitiría renovar las interacciones de los estudiantes y las evaluaciones propuestas por los profesores, no sólo en clase de francés, sino también en las clases de francés segunda lengua y de francés lengua materna. 